\title{
The High Mountain Asia glacier contribution to sea-level rise from 2000 to 2050
}

\author{
Liyun ZHAO, ${ }^{1,2}$ Ran DING, ${ }^{1}$ John C. MOORE ${ }^{1,2,3}$ \\ ${ }^{1}$ College of Global Change and Earth System Science, Beijing Normal University, Beijing, China \\ ${ }^{2}$ Joint Center for Global Change Studies, Beijing, China \\ ${ }^{3}$ Arctic Centre, University of Lapland, Rovaniemi, Finland \\ Correspondence: John C. Moore <john.moore.bnu@gmail.com>
}

\begin{abstract}
We estimate all the individual glacier area and volume changes in High Mountain Asia (HMA) by 2050 based on Randolph Glacier Inventory (RGI) version 4.0, using different methods of assessing sensitivity to summer temperatures driven by a regional climate model and the IPCC A1B radiative forcing scenario. A large range of sea-level rise variation comes from varying equilibrium-line altitude (ELA) sensitivity to summer temperatures. This sensitivity and also the glacier mass-balance gradients with elevation have the largest coefficients of variability (amounting to $\sim 50 \%$ ) among factors examined. Prescribing ELA sensitivities from energy-balance models produces the highest sea-level rise $\left(9.2 \mathrm{~mm}\right.$, or $0.76 \%$ of glacier volume $\left.\mathrm{a}^{-1}\right)$, while the ELA sensitivities estimated from summer temperatures at Chinese meteorological stations and also from $1^{\circ} \times 1^{\circ}$ gridded temperatures in the Berkeley Earth database produce 3.6 and $3.8 \mathrm{~mm}$, respectively. Different choices of the initial ELA or summer precipitation lead to $15 \%$ uncertainties in modelled glacier volume loss. RGI version 4.0 produces $20 \%$ lower sea-level rise than version 2.0. More surface mass-balance observations, meteorological data from the glaciated areas, and detailed satellite altimetry data can provide better estimates of sea-level rise in the future.
\end{abstract}

KEYWORDS: glacier mass balance, glacier modelling, mountain glaciers

\section{INTRODUCTION}

Many studies have reported that High Mountain Asia (HMA) glaciers have lost mass over the past few decades, although with significant regional differences (e.g. Bolch and others, 2012; Yao and others, 2012; Gardner and others, 2013). The response of these glaciers to future climate change is a topic of concern especially to the many people who rely on glacier-fed rivers for purposes such as irrigation. A key problem in HMA is the lack of glaciological and climate observations on glaciers themselves. The differences in climate and glacier types across the region exacerbate the difficulties due to the lack of ground truth. Hence future response of glaciers has been estimated using statistical approaches, with considerable extrapolation from observation (e.g. Marzeion and others, 2012; Radić and others, 2014; Zhao and others, 2014).

A brief summary of previous estimates of the HMA contribution to sea-level rise under climate forcing during the 21 st century illustrates the wide range of estimates found and hence uncertainties in the average estimate. Radic and others (2014) used statistical downscaling of global climate model output (typically at $200 \mathrm{~km}$ resolution) to drive the mass balance of individual mass balance globally, validating and tuning their model on a regional scale using measurements on 137 glaciers (10 in HMA). This produces a sealevel contribution of $18 \pm 5 \mathrm{~mm}$ by 2100 under the Intergovernmental Panel on Climate Change (IPCC) A1B scenario. A similar approach by Marzeion and others (2012) found $\sim 15 \pm 10 \mathrm{~mm}$ of global sea-level rise from HMA under RCP6.0 (which is similar to A1B) by 2100 . Zhao and others (2014) used a novel SMB-altitude parameterization fitted to observational data, driven by a relatively highresolution regional climate model, and also an estimate tuned to match satellite observations of glacier thickness changes in HMA from 2003 to 2009. Ice volume loss over the $2000-50$ period amounted to $\sim 10 \mathrm{~mm}$ of sea-level rise, but only $5 \mathrm{~mm}$ in the tuned simulation.

The differences in estimates may be caused by both observational deficiencies and statistical methodology. Observational data quality has improved considerably over recent years, mainly through satellite-based inventories of glacier outlines. In the HMA region the Randolph Glacier Inventory (RGI) version 2.0 (Arendt and others, 2012) contains outlines of glacier complexes rather than individual glaciers, which may lead to considerable bias in the glacier volume estimate due to the nonlinearity of the volume-area scaling relationship (Grinsted, 2013). The newly distributed RGI version 4.0 (Arendt and others, 2014) makes improvements in the separation of glacier complexes into individual glaciers in most regions. In particular, all the glacier complexes in Central Asia are divided using semi-automated algorithms (Bolch and others, 2010; Kienholz and others, 2013).

In this paper, we attempt to provide a better estimate of total HMA contribution to sea-level rise, and assess its regional variability and uncertainty across HMA. We simulate glacier area and volume changes for every individual glacier in HMA. In total we produce four estimates that use different methods for calibrating ELA sensitivity with RGI 4.0. Method 1 takes zonal mean ELA sensitivity coefficients for both temperature and precipitation from Rupper and Roe (2008); method 2 takes zonal mean ELA sensitivity to temperature alone from Rupper and Roe (2008); method 3 takes calculated ELA sensitivity to temperature using daily temperature data from the nearest Chinese meteorological station to each individual glacier; method 4 is similar to 


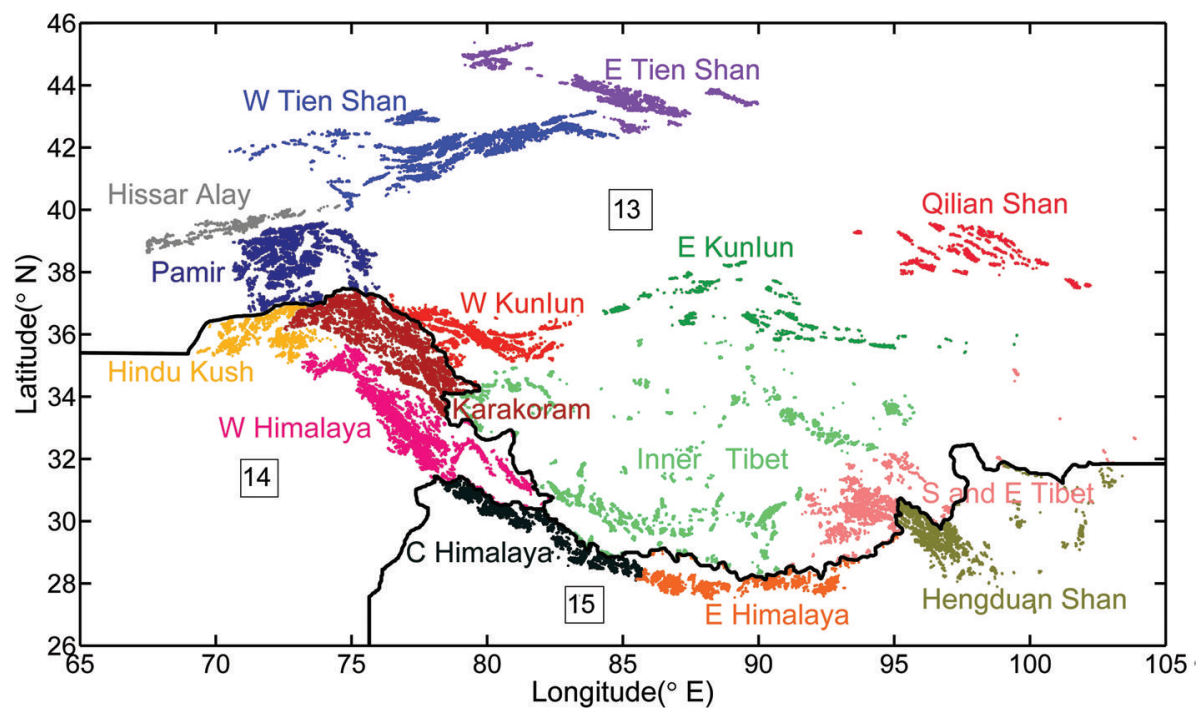

Fig. 1. Sub-regions of HMA in RGI 4.0. The black curves represent the boundaries between regions 13 (Central Asia), 14 (South Asia West) and 15 (South Asia East).

method 3 but uses gridded temperature data from the Berkeley Earth project (Rohde and others, 2013; http:// berkeleyearth.org/data/).

\section{STUDY REGION AND DATA}

Our study region covers $\mathrm{HMA}\left(25-50^{\circ} \mathrm{N}, 65-105^{\circ} \mathrm{E}\right)$, which corresponds to the regions of Central Asia, South Asia West and South Asia East in the RGI 4.0 (Fig. 1). This region contains a total of 83460 glaciers and a glacierized area of $118263 \mathrm{~km}^{2}$ according to RGI 4.0, while in RGl 2.0 it contained 67028 glaciers and a glacierized area of $129052 \mathrm{~km}^{2}$. Almost all the glacier number increases are in Central Asia due to separation of glacier complexes into individual glaciers (Fig. 2). The reduction in the observed average area of individual glaciers leads to lower estimates of total ice volume from volume-area scaling relations.

The inventory data contain a variety of sources, inaccuracies and reference datums (at least WGS84). RGI data for China, the northern slopes of the Himalaya and the northeastern part of Karakoram are based on the first Chinese glacier inventory (Shi and others, 2009), made over the 1960s-80s. Most glacier data in HMA from outside China are from the late 1990s or 2000s. For simplicity, we take 1980 and 2000 as the beginning years of our model for glaciers inside and outside China, respectively.

In addition to the glacier area and volume, we also need ELAs for each glacier at the start of the simulation period. The ELA for all glaciers in 1980, ELA ${ }^{1980}$, can be obtained by interpolating the ELA contour data from the Chinese glacier inventory, which was generally estimated from aerial photogrammetry. This interpolated ELA was used in Zhao and others (2014). The RGI 4.0 provides median altitude for every glacier. We compare the interpolated ELA ${ }^{1980}$ with median altitude of glaciers inside China, and find good agreement (Fig. 3), with a correlation coefficient of 0.92 ; the mean and standard deviation of the difference are $-61.5 \mathrm{~m}$ and $284 \mathrm{~m}$, respectively. Therefore, median altitude is a good proxy for ELA ${ }^{1980}$ in HMA, a result consistent with findings based on the 'Glacier Area Mapping for Discharge
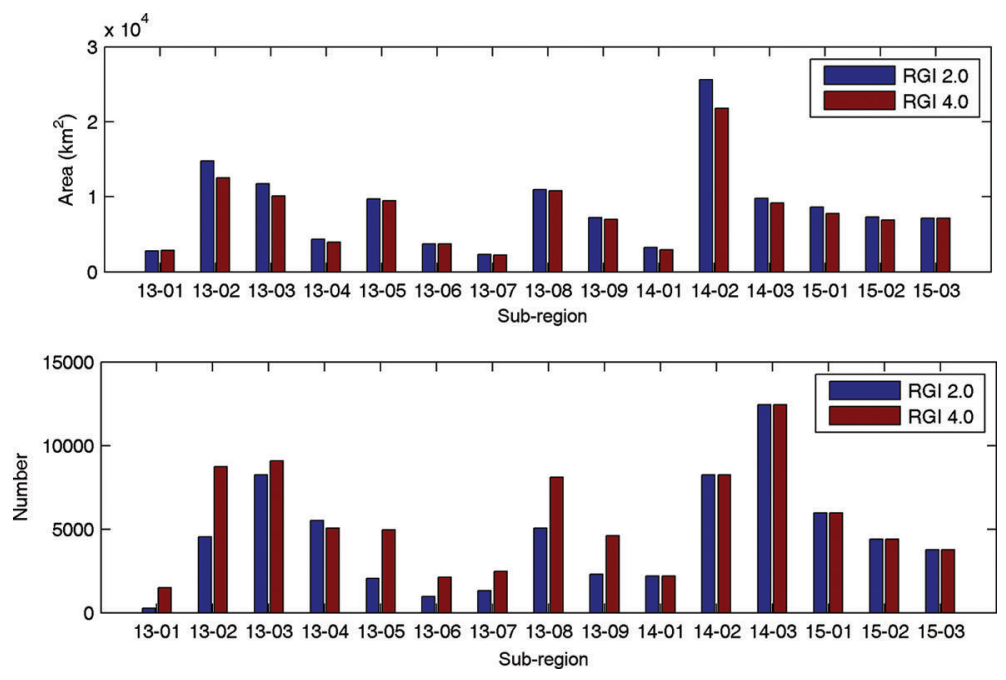

Fig. 2. RGI 2.0 and RGI 4.0 numbers of glaciers and area in each sub-region. Figure 1 labels corresponding to 13-01 to 13-09 are Hissar Alay, Pamir, W Tien Shan, E Tien Shan, W Kunlun, E Kunlun, Qilian Shan, Inner Tibet and S and E Tibet. 14-01 to 14-03 are Hindu Kush, Karakoram and W Himalaya. 15-01 to 15-03 are C Himalaya, E Himalaya and Hengduan Shan. 

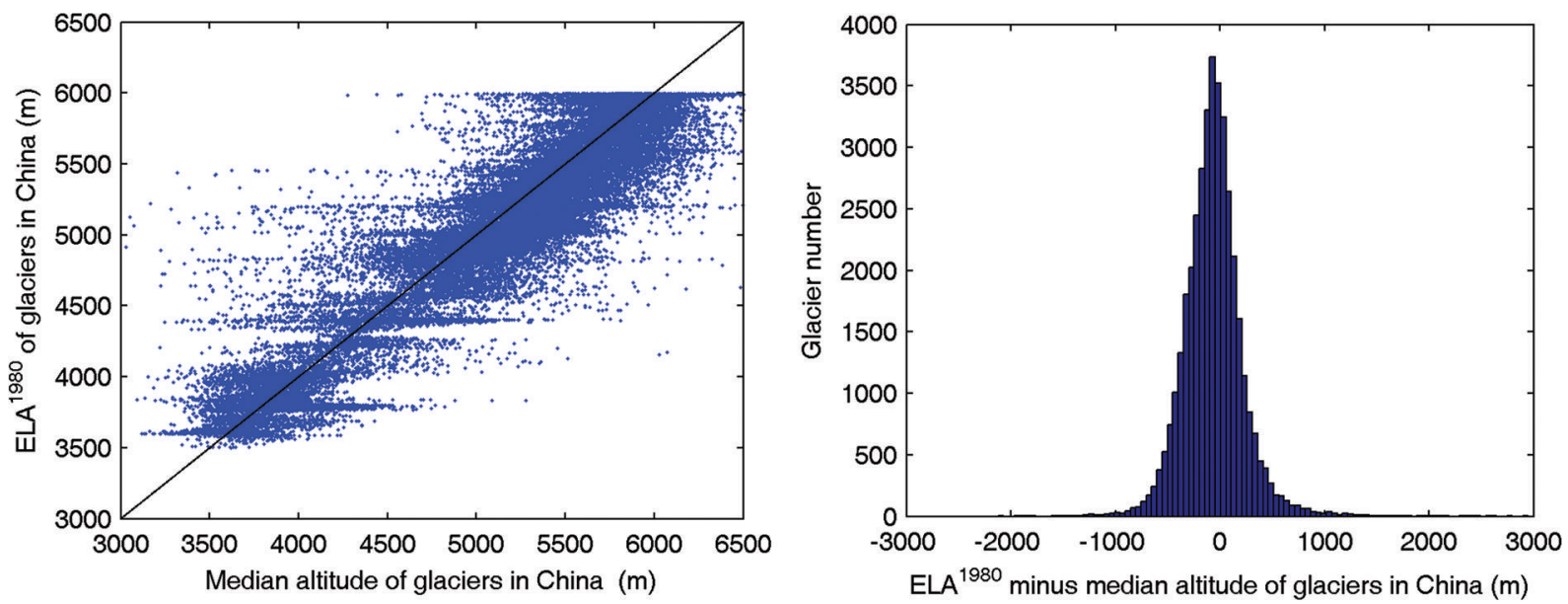

Fig. 3. $\mathrm{ELA}^{1980}$ vs median altitude (left) and the histogram (right) of the difference between ELA ${ }^{1980}$ and median altitude of glaciers in China from $\mathrm{RGl}$ 4.0. The black line is the $1: 1$ line.

from the Asian Mountains' glacier inventory (Nuimura and others, 2015). Note that this relation holds because many glaciers were approximately in steady state in 1980; at present there are glaciers where the ELA is above the top of the glacier and median altitude is not a good approximation to ELA. For better methodological consistency across the whole of HMA, here we use median altitude from RGI 4.0 as the initial ELA (1980 inside, and 2000 outside, China). We use the Shuttle Radar Topography Mission (SRTM) version 4.1 (void-filled version; Jarvis and others, 2008) digital elevation model (DEM) with $90 \mathrm{~m}$ horizontal resolution to estimate the elevation range spanned by each glacier. Except for the revised RGI and the initial ELA, the data used here are as in Zhao and others (2014).

Climate forcing is required to simulate variation in ELA and we use temperature and precipitation change trends from the Regional Climate Model version 3.0 (RegCM3) whose horizontal resolution is $25 \mathrm{~km}$ and model domain covers all of China and surrounding East Asia areas (Gao and others, 2012). The RegCM3 model was one-way nested in the $125 \mathrm{~km}$ resolution global climate model, MIROC3.2_hires, which was forced using the IPCC A1B greenhouse gas scenario. The model makes simulations from 1948 to 2100; we use results from 1980 to 2050 here.

\section{METHODS}

We use four different methods here to estimate sea-level rise contributions from HMA between 2001 and 2050. Critical factors in all methods are individual glacier ELA reconstructions and their sensitivities to climate change. The ELA sensitivity coefficients with respect to temperature and precipitation are used to estimate ELA variation driven by trends in temperature and precipitation from RegCM3. The ELA in the beginning year takes the value of median elevation in RGI 4.0 for each glacier. Method 1 uses prescribed ELA sensitivities to both summer (June-JulyAugust or JJA) temperatures and annual precipitation. Method 2 is like method 1 but uses only summer (JJA) temperatures. Method 3 uses ELA sensitivities calculated from temperature records from Chinese stations, and method 4 uses gridded temperature data. In methods 2-4, we use only the dependence on summer temperatures. Calculating the ELA sensitivity coefficient to annual precipitation in an analogous way to temperature in methods 3 and
4 is problematic, since neither precipitation recorded at meteorological stations nor gridded precipitation data are representative of those on the glacier because of strong and localized orographic effects.

The algorithm (Fig. 4) for estimating glacier change is as follows. We start from known glacier outlines from RGI 4.0 and glacier elevation distribution from SRTM 4.1. We simply parameterize the annual $\mathrm{SMB}$ as a function of altitude relative to the ELA for each glacier. We use the available SMB measurements on eight glaciers to calculate two or three SMB gradients (Zhao and others, 2014). The $\mathrm{SMB}$-altitude profile is constructed for every glacier by using its own ELA and two or three SMB gradients estimated from the nearest glacier with in situ SMB measurements. Integrating the SMB over each glacier gives the volume change rate, which is converted to an area change rate using volume-area scaling, $V=c S^{\gamma}$, where $V$ and $S$ are volume $\left(\mathrm{km}^{3}\right)$ and surface area $\left(\mathrm{km}^{2}\right)$. Zhao and others (2014) found that various reported scaling coefficients make only about $10 \%$ differences in sea-level contribution, and here we choose $c=0.0380$ and $\gamma=1.290$ (Moore and others, 2013). The area change rate then gives the new glacier terminus position and hence the new outline for the next year by assuming all the decrease in area takes place in the lowest parts of the glacier, i.e. the glacier becomes shorter not narrower. Combining the glacier elevation distribution, the SMB and the new outline, we obtain glacier elevation distribution for the next year. Note that the SMB-altitude profile on each glacier is evolved annually as the ELA

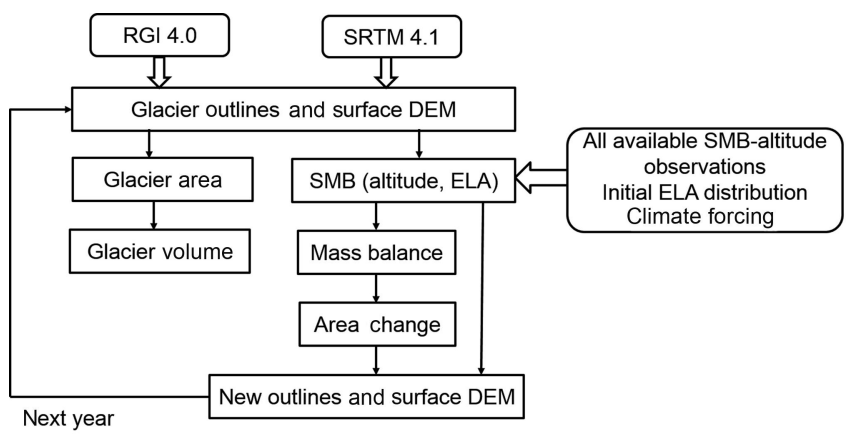

Fig. 4. The algorithm used to determine each glacier's annual evolution from initial conditions. 


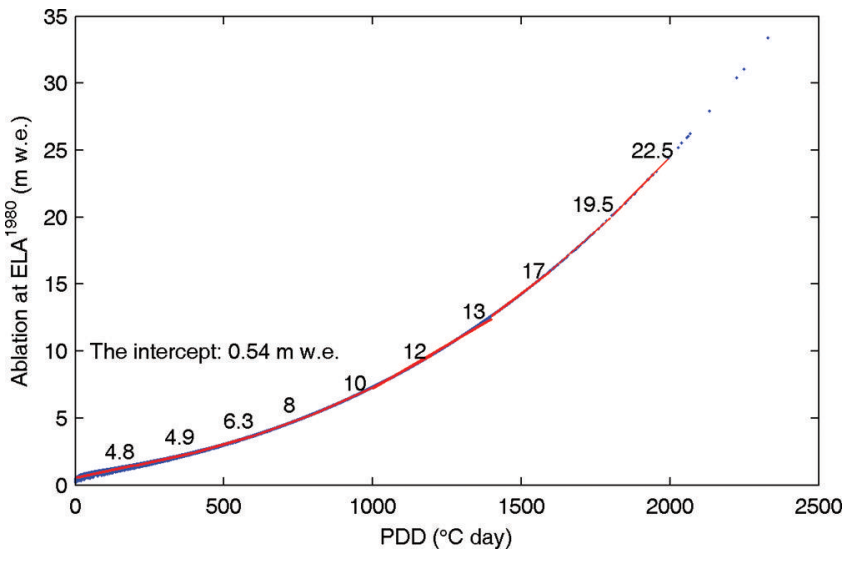

Fig. 5. Ablation at each glacier's initial ELA calculated by Eqn (2) as a function of positive degree-days (PDD) at initial ELA using JJA temperatures from the nearest meteorological station and using gridded data. The initial ELA takes the value of median elevation in RGl 4.0 for each glacier. The red lines are piecewiselinear fitted functions with gradients (degree-day factors or DDF (mm w.e. $\left.{ }^{\circ} \mathrm{C}^{-1} \mathrm{~d}^{-1}\right)$ marked). There is both spatial variability and a sizeable spread in DDF across the region, with values reported ranging between 3 and $15 \mathrm{mmw}$.e. ${ }^{\circ} \mathrm{C}^{-1} \mathrm{~d}^{-1}$ (e.g. Kayastha and others, 2003; Zhang and others, 2006).

changes, driven by trends in temperature and precipitation from the climate model.

\subsection{ELA sensitivities prescribed from Rupper and Roe (2008)}

ELA sensitivities can be expressed as coefficients with respect to temperature and precipitation. Method 1 follows Zhao and others (2014) and calculates the ELA in the $n$th year from the beginning year as

$$
\mathrm{ELA}_{n}=\mathrm{ELA}_{0}+\alpha \Delta T+\beta \Delta P,
$$

where $\Delta T$ and $\Delta P$ are the net change of summertime mean air temperature and annual precipitation between the beginning year and the $n$th year, which are calculated using the averaged change rates of summertime air temperature and annual precipitation from 1980 to 2050 from RegCM3 output. The coefficients $\alpha\left(\mathrm{m}^{\circ} \mathrm{C}^{-1}\right)$ and $\beta\left(\mathrm{m} \mathrm{m}^{-1}\right)$ are the sensitivity of ELA shift to air temperature change $\left({ }^{\circ} \mathrm{C}\right)$ and precipitation change $(\mathrm{m})$, respectively, which are zonal mean values from energy-balance modelling of glaciers in HMA by Rupper and Roe (2008).

Method 2 assesses the effect of excluding the precipitation sensitivity and estimates ELA change with prescribed temperature sensitivity alone.

\subsection{ELA sensitivities calculated from temperature records}

Methods 3 and 4 estimate ELA sensitivity to summertime mean air temperature, $\alpha$, for individual glaciers based on time series of ELA and temperature during 1980-2012. ELA every year is implicitly obtained by estimating ablation at the ELA in two separate ways - an empirical formula and the degree-day method - and then adjusting the altitude such that the two functions are equal. The first way is the empirical formula (Kotlyakov and Krenke, 1982; Krenke and Khodakov, 1997), which is fitted to glaciers in the Pamir and Caucasus, but structurally similar formulae have also been used for Tien Shan glaciers (Liu and Ding, 1988): the ablation at the ELA is taken to be

$$
\left.a\right|_{\mathrm{ELA}}=1.33\left(\left.\bar{T}\right|_{\mathrm{ELA}}+9.66\right)^{2.85},
$$

in which $\left.\bar{T}\right|_{\text {ELA }}$ is the mean June-August temperature at the ELA and is estimated by extrapolation from daily temperature records with a vertical lapse rate of $0.0065^{\circ} \mathrm{C} \mathrm{m}^{-1}$. The second way to calculate ablation at the ELA is to use a positive degree-day (PDD) model (Braithwaite, 1984). We multiply the sum of daily mean air temperatures at the ELA that are above zero in June-August (JJA) by a suitable degree-day factor (DDF). The typical DDF values for snow and ice are 3 and $8 \mathrm{~mm}$ w.e. ${ }^{\circ} \mathrm{C}^{-1} \mathrm{~d}^{-1}$ respectively for the Greenland ice sheet (Cuffey and Paterson, 2010). There is both regional variability and a sizeable spread in DDF across the region, with reported values ranging between 3 and $15 \mathrm{~mm}$ w.e. ${ }^{\circ} \mathrm{C}^{-1} \mathrm{~d}^{-1}$ (e.g. Kayastha and others 2003; Zhang and others 2006). Although PDD, the sum of positive daily temperature, may be positive, the mean daily temperature may be negative over the same period.

In order to determine the DDF and sublimation term in the PDD model, we calculate ablation at the ELA in the beginning year (1980 for glaciers in China and 2000 for glaciers outside China) using Eqn (2), and also the PDD at the ELA in JJA of the beginning year using temperature input data. We investigate the relation between ablation and PDD at the ELA in the beginning year (Fig. 5). DDF is not a constant (Fig. 5) but can be parameterized as a piecewise linear function of PDD. This DDF as a function of PDD is then used in the PDD model for years 1981-2012. This piecewise linear function means that the DDF value used for a given PDD is a weighted average of a few DDF values (Fig. 5). Sublimation is the dominant ablation mechanism in very cold environments where surface temperature seldom reaches the melting point even in summer (Cuffey and Paterson, 2010). Here sublimation when PDD is close to zero corresponds to the intercept value of the ablation-PDD curve, $540 \mathrm{~mm}$.

The unknown ELA for every year in the period from the beginning year to 2012 for individual glaciers must be found numerically by comparing the ablation as a function of altitude from Eqn (2) with the ablation calculated by the PDD model as a function of altitude. The ablation calculated by the two methods will be equal at the ELA. Thus for each glacier we produce annual ELA values for mean JJA temperature from the beginning year to 2012. The ELA sensitivity to warming is then the linear regression COefficient of ELA versus JJA temperature for each glacier.

For the daily temperature input used in Eqn (2) and the PDD method, we use two datasets: method 3 uses the nearest Chinese meteorological station to the glacier, while method 4 uses the gridded data from the Berkeley Earth project.

\subsubsection{Temperature records from Chinese stations}

The pattern of ELA sensitivity to temperature change is shown in Figure 6b. Sensitivities decrease from the Himalaya and northern Tien Shan to the inner Tibetan Plateau. The ELA sensitivities are generally smaller than those prescribed from Rupper and Roe (2008) (Fig. 6a). We only used Chinese stations, and there are few stations on the periphery of the Tien Shan, or outside China in the Karakoram, western Himalaya and western Kunlun. As a result, the sensitivities are patchy and vary quite unreasonably in these regions. For example, there are modelled ELA sensitivity coefficients smaller than $50 \mathrm{~m}^{\circ} \mathrm{C}^{-1}$ in the Tien 

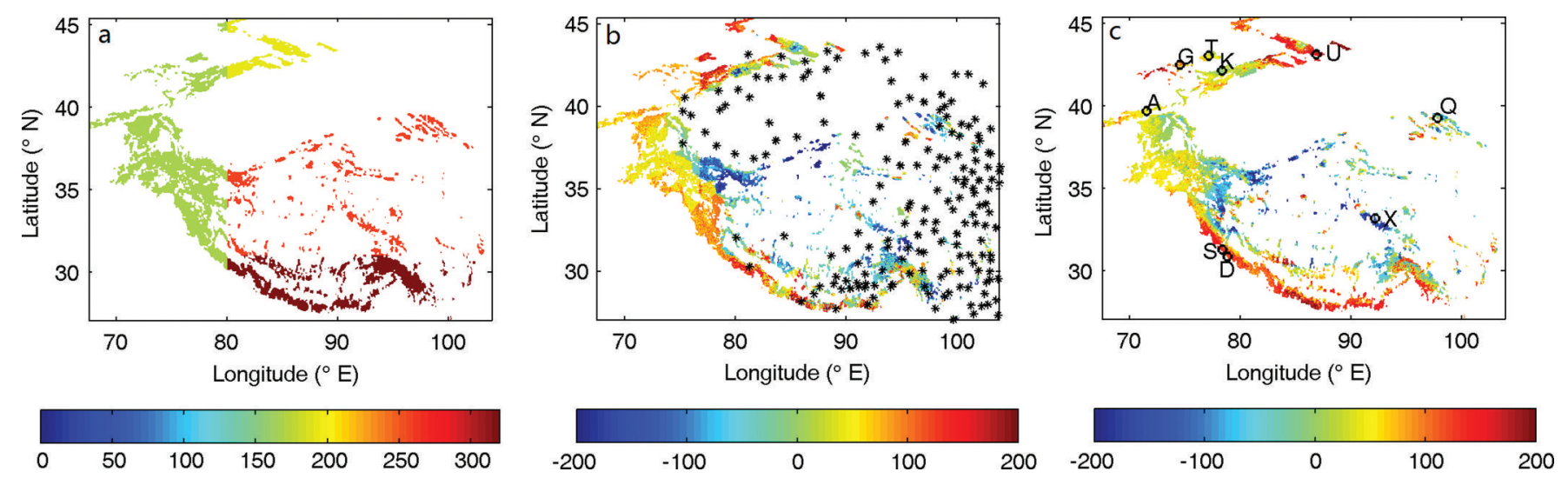

Fig. 6. ELA sensitivity $\left(\mathrm{m}^{\circ} \mathrm{C}^{-1}\right.$ ) to JJA mean temperature (a) used in methods 1 and 2, based on energy-balance modelling by Rupper and Roe (2008); (b) used in method 3 with daily temperatures from nearest Chinese meteorological station; and (c) used in method 4 based on gridded daily temperatures in the Berkeley Earth temperatures dataset. Black stars in (b) mark locations of meteorological stations in western China. Black circles in (c) mark locations of glaciers presented in Figure 7 by the first letter of the glacier name.

Shan, which is not plausible given observations of recent glacier wastage there (Pieczonka and Bolch, 2015).

Notice that there are negative values of ELA warming sensitivity in Kunlun, the inner Tibetan Plateau and the Qilian Shan, which means that ELA decreases as the summer mean temperature increases, perhaps due to increased snowfall dominating the glacier mass balance as temperatures increase. Indeed, Gardner and others (2013) found glacier elevation increases between 2003 and 2009 at locations in western Kunlun and the inner Tibetan Plateau, even though temperatures were increasing (Wei and Fang, 2013). But negative values of ELA warming sensitivity may also indicate problems with our method, and alternative approaches to tackle this issue are underway.

\subsubsection{Berkeley Earth temperatures}

To address the sparse distribution of observational data, we turn to the sophisticated interpolation and data filling available in gridded global near-surface temperature datasets. We use daily gridded $1^{\circ} \times 1^{\circ}$ temperature data from the Berkeley Earth project (Rohde and others, 2013; http:// berkeleyearth.org/data/) which are generated by supposedly using all available station data and a bespoke interpolation method.

The relationship between ablation at ELA and PDD in JJA in the beginning year is the same as that found using the station data (Fig. 5). The pattern of ELA warming sensitivity is shown in Figure 6c. The general picture is similar to, but less patchy than, that obtained using the station data (Fig. 6b). Sensitivities are larger in the eastern Tien Shan, Kunlun and Hengduan Shan, but smaller in the Pamir, western Tien Shan, Karakoram and western Himalaya, than derived from the station data.

\subsection{Validation of different reconstructed ELAs}

As a validation of the methods we calculated the ELA for nine glaciers in China, India and Kyrgyzstan (World Glacier Monitoring Service; Fujita and others, 2000; Pu and others, 2008) - Abramov, Golubin, Tuyuksu, Karabatkak, Urumqihe S. No 1, Qiyi, Shaune Garang, Dokriani and Xiaodongkemadi glaciers - during their observational intervals. We compare the observed ELA time series with the modelled ELA by similarities of decadal trends and also annual variability (Fig. 7). Method 1 is perhaps the best regarding decadal trend. The significance levels for the detrended ELA correlation coefficients suggest that method 4 is perhaps the best regarding annual variability for these glaciers. However, no method is obviously better than the others, whether for decadal trends or annual variability. Clearly, we cannot say which method gives the best results since there are too few glaciers to validate, and the validation periods are relatively short. Even the trends are subject to large uncertainties in observations and cannot, in general, be used to rule out methods. More glacier field measurements are required to provide more reliable modelling.

\section{RESULTS}

\subsection{Comparison using different ELA sensitivities}

Table 1 provides detailed results for the sub-regions, while the results using different ELA sensitivities are summarized in Table 2. Different ELA sensitivities lead to large differences of volume and area loss. The sea-level contribution from 2000 to 2050 is $9.2 \mathrm{~mm}$ using method 1 but $10.8 \mathrm{~mm}$ using method 2 (which excludes ELA sensitivities to precipitation). Because the precipitation modelled by RegCM3 has increasing trends in the Pamir, Karakoram, western Himalaya, Tien Shan and eastern Tibetan Plateau regions (Zhao and others, 2014), modelled ELAs including the ELA sensitivities to precipitation are lower than those without them, which leads to less glacier mass loss. Our calculated ELA sensitivity coefficients (methods 3 and 4) are generally smaller than the prescribed ones (methods 1 and 2) from Rupper and Roe (2008; Fig. 6). The sea-level contribution from 2000 to 2050 is $3.6 \mathrm{~mm}$ using method 3 station data and $3.8 \mathrm{~mm}$ using method 4 gridded data (Table 2). Since there are negative ELA sensitivities using Chinese station data and gridded data in some sub-regions, there are far fewer retreating glaciers under methods 3 and 4 than the other methods, which seems dubious.

\subsection{Comparison with elevation change from 2003 to 2009}

We estimate elevation changes for individual glaciers directly from our simulated volume and area changes, then calculate the average rate of elevation change for all the glaciers in each sub-region (assuming an ice density of $900 \mathrm{~kg} \mathrm{~m}^{-3}$ ) and compare them with remote-sensing 

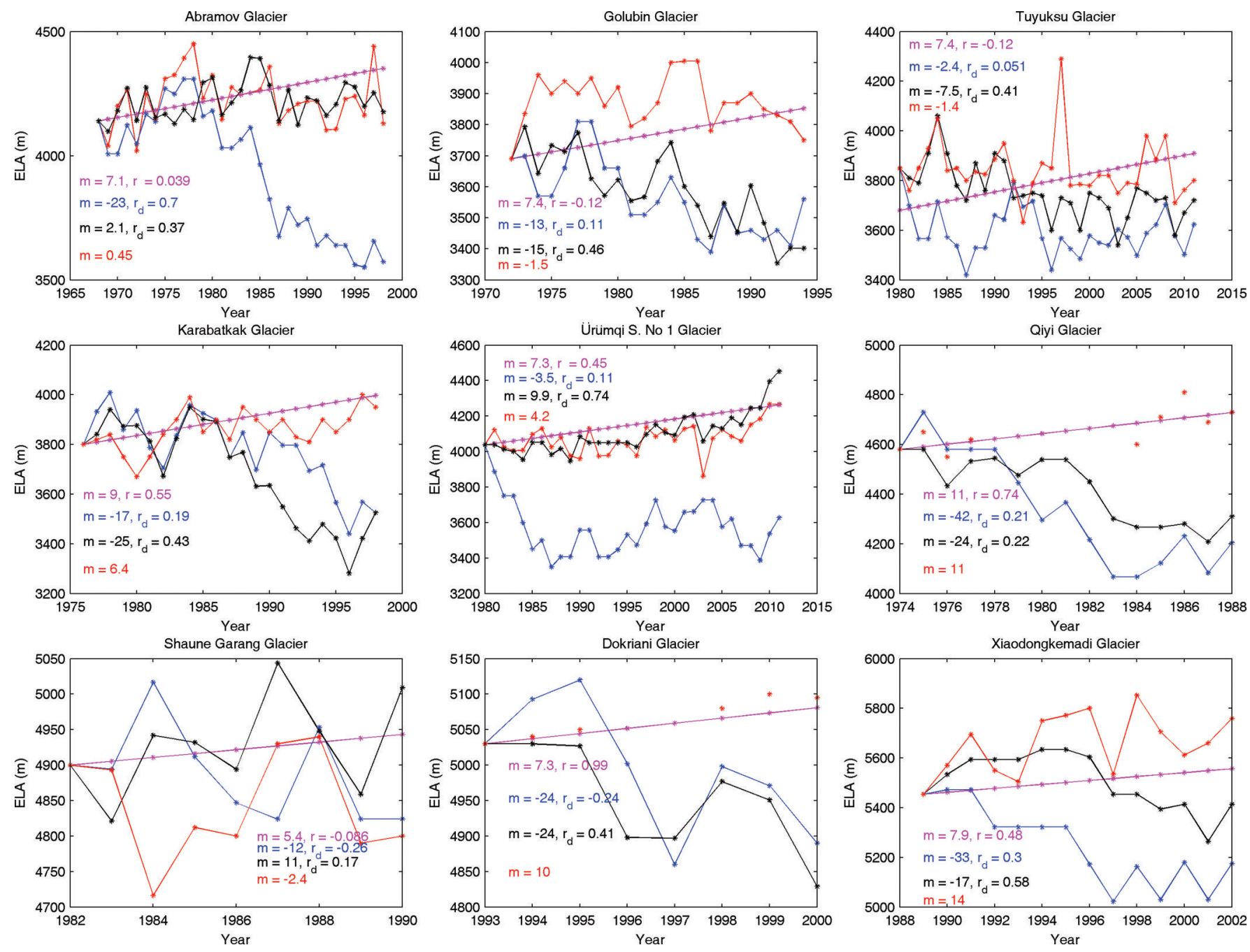

Fig. 7. Modelled and observed ELA variability. Red curves shows field measurements of ELA; magenta uses method 1 where ELA comes from prescribed ELA sensitivities to summer mean temperature and annual precipitation; blue curves are from method 3 using station data; black curves are from method 4 using the Berkeley gridded data. The ELA gradients $\left(m ; \mathrm{m} \mathrm{a}^{-1}\right)$, the correlation coefficient between the observations and colour-coded methods $(r)$ and the detrended correlation coefficient $\left(r_{\mathrm{d}}\right)$ are given in each panel. Thus $m$ represents similarity in ELA decadal trend and $r_{\mathrm{d}}$ shows similarity on annual timescales. For method $4, r_{\mathrm{d}}$ is significant at the $95 \%$ level for all except Qiyi and Dokriani glaciers. The locations of the nine glaciers are shown in Figure 6c.

estimates from 2003 to 2009 from Gardner and others (2013) in Table 3. Methods 1 and 2 using prescribed ELA coefficients give generally more negative elevation change rates than observed in all the sub-regions except the western Himalaya. Method 3 based on meteorological stations produces less negative elevation change rates than observed in all the sub-regions except in Hissar Alay, Pamir and central Himalaya, and similar elevation change rates in Hindu Kush and Karakoram, western Kunlun, central Himalaya and Tien Shan. Method 4 using Berkeley Earth gridded data yields generally less negative elevation changes than in Gardner and others (2013) except in the eastern Tien Shan and western Kunlun. We find that the area-weighted elevation change for the whole region from Gardner and others (2013) is about one-third of that from methods 1 and 2 using prescribed ELA sensitivities, but twice that from methods 3 and 4 using calculated ELA sensitivities. We also note that there are discrepancies between authors producing Ice, Cloud and land Elevation Satellite (ICESat)-based altimetry estimates (e.g. Gardner and others (2013) used the RGl, while Kääb and others (2015) did their own classification) due to the inventories they used (manual classification of ICESat footprints versus the RGI), in particular over the eastern Nyainqêntanglha Shan.

\subsection{Comparison using different initial ELA in the beginning year}

ELA is a key parameter in our algorithm to determine each glacier's annual evolution. It depends on not only ELA sensitivities to climate but also ELA in the beginning year. We performed sensitivity experiments with respect to the initial ELAs using method 1. Although median elevation seems a good proxy of the interpolated ELA in the beginning year (section 2), we do find an obvious difference between results using median elevation and those using the ELA interpolated from the first Chinese glacier inventory. The glacier volume loss from 2000 to 2050 is $9.2 \mathrm{~mm}$ of global sea level using method 1 with median elevations as the ELA in the beginning year, but $7.9 \mathrm{~mm}$ using the interpolated ELA in the beginning year. We also used method 1 taking the ELA in the beginning year as the elevation of the 60th percentile of the cumulative area above the glacier terminus (denoted as 60\%-area elevation hereafter), and found a sealevel equivalent loss of $10.2 \mathrm{~mm}$ in the same period. 
Table 1. Estimated annually averaged glacier volume and area changes for the sub-regions of HMA from 2000 to 2050 using methods 1,3 and 4 (M1, M3 and M4) based on RGI 4.0. The volume loss ( $\mathrm{mm}$ sea-level equivalent during 2000-50) is calculated by assuming ice density of $900 \mathrm{~kg} \mathrm{~m}^{-3}$ and ocean area of $362 \times 10^{12} \mathrm{~m}^{2}$. Method 1 takes zonal mean ELA sensitivity coefficients with respect to temperature and precipitation prescribed from Rupper and Roe (2008; Fig. 6a); methods 3 and 4 use ELA sensitivity to temperature calculated using daily temperature data from the nearest Chinese meteorological station to individual glaciers (Fig. 6b) and gridded data from the Berkeley Earth project (Fig. 6c), respectively. Median elevations from RGl 4.0 are taken as ELA in the beginning year

\begin{tabular}{|c|c|c|c|c|c|c|c|c|c|c|}
\hline \multirow[t]{3}{*}{ Sub-region No. } & \multirow[t]{3}{*}{ Sub-region in RGI } & \multicolumn{3}{|c|}{ Volume loss rate } & \multicolumn{3}{|c|}{ Area loss rate } & \multicolumn{3}{|c|}{ Global sea-level rise $2000-50$} \\
\hline & & M1 & M3 & M4 & M1 & M3 & M4 & M1 & M3 & M4 \\
\hline & & $\% a^{-1}$ & $\% a^{-1}$ & $\% a^{-1}$ & $\% a^{-1}$ & $\% a^{-1}$ & $\% a^{-1}$ & $\mathrm{~mm}$ & $\mathrm{~mm}$ & $\mathrm{~mm}$ \\
\hline 13-01 & Hissar Alay & -1.52 & -1.05 & -0.58 & -1.47 & -0.97 & -0.47 & 0.41 & 0.29 & 0.16 \\
\hline $13-02$ & Pamir & -1.05 & -0.59 & -0.27 & -1.10 & -0.54 & -0.21 & 1.37 & 0.78 & 0.35 \\
\hline $13-04$ & E Tien Shan & -1.24 & -0.52 & -1.41 & -1.22 & -0.67 & -1.39 & 0.27 & 0.12 & 0.30 \\
\hline 13-05 & W Kunlun & -0.26 & 0.25 & 0.13 & -0.40 & -0.01 & -0.03 & 0.29 & -0.29 & -0.16 \\
\hline $13-06$ and $13-08$ & E Kunlun and Inner Tibet & -0.59 & 0.14 & 0.05 & -0.61 & -0.08 & -0.14 & 0.70 & -0.18 & -0.06 \\
\hline $13-07$ & Qilian Shan & -1.55 & 0.16 & -0.06 & -1.47 & -0.25 & -0.29 & 0.21 & -0.02 & 0.01 \\
\hline $13-09$ & $\mathrm{~S}$ and $\mathrm{E}$ Tibet & -1.35 & 0.17 & -0.26 & -1.37 & -0.18 & -0.37 & 0.78 & -0.12 & 0.17 \\
\hline 14-01 and 14-02 & Hindu Kush and Karakoram & -0.46 & -0.31 & -0.28 & -0.46 & -0.27 & -0.24 & 1.71 & 1.13 & 1.02 \\
\hline $14-03$ & W Himalaya & -0.57 & -0.62 & -0.44 & -0.62 & -0.57 & -0.40 & 0.45 & 0.49 & 0.35 \\
\hline $15-01$ & C Himalaya & -1.08 & -0.74 & -0.67 & -1.08 & -0.71 & -0.62 & 0.79 & 0.55 & 0.50 \\
\hline \multirow[t]{2}{*}{$15-03$} & Hengduan Shan & -1.56 & -0.03 & -0.42 & -1.61 & -0.36 & -0.53 & 0.79 & 0.02 & 0.25 \\
\hline & All HMA & -0.76 & -0.34 & -0.30 & -0.85 & -0.37 & -0.19 & 9.18 & 3.63 & 3.80 \\
\hline
\end{tabular}

\section{CONCLUSION AND DISCUSSION}

The sea-level contribution from HMA between 2001 and 2050 is estimated based on two distinct approaches to determining ELA sensitivity to climate change. This sensitivity is the most crucial parameter in estimating the SMB of individual glaciers. The first way is to prescribe ELA sensitivities from energy-balance modelling done by Rupper and Roe (2008). This produces a volume loss by 2050 of $9.2 \mathrm{~mm}$ global sea-level rise if ELA sensitivities to both summer temperature and annual precipitation are taken into account (method 1) and $10.8 \mathrm{~mm}$ if ELA sensitivity to precipitation is excluded (method 2). In this case, increases in precipitation offset $\sim 18 \%$ of the sea-level contribution caused by the temperature warming.

The second way is based on estimating temperature at the ELA and a degree-day method. Daily temperatures at the ELA were calculated using records from the nearest Chinese meteorological station (method 3) and also from Berkeley Earth gridded temperatures (method 4). The two methods produce similar ELA sensitivity coefficients in most subregions (the gridded data give a less patchy picture), and both give smaller 2050 volume losses of $3.6 \mathrm{~mm}$ and
$3.8 \mathrm{~mm}$ sea-level equivalent than using the prescribed ELA sensitivity. Comparing the average elevation change rates with remote-sensing estimates from 2003 to 2009 shows that the calculated ELA sensitivities lead to generally too small mass changes in almost all sub-regions, suggesting further investigation of the method (e.g. the parameters and coefficients used).

Comparing different methods of estimating initial ELAs using method 1 suggests a spread of $\sim 20 \%$ in volume loss. Simulated ice losses were equivalent to sea-level rises of 7.9, 9.2 and $10.2 \mathrm{~mm}$ using the interpolated ELA from the first Chinese glacier inventory, median elevation provided by RGI 4.0, and 60\%-area elevation, respectively.

Zhao and others (2014) used method 1 on RGI 2.0 with the interpolated ELA in the beginning year. RGI 4.0 makes improvements over RGI 2.0 in the separation of glacier complexes into individual glaciers (Section 2), leading to a $22 \%$ increase in glacier numbers but a $30 \%$ decrease in total volume in 2000. This decreases the sea-level rise contribution from HMA glaciers between 2001 and 2050 from $\sim 10 \mathrm{~mm}$ using RGl 2.0 to $7.9 \mathrm{~mm}$, or $\sim 20 \%$. RGI 4.0 produces lower total volume loss but faster volume/area

Table 2. Estimation of glacier status and glacier volume and area changes of all glaciers in HMA from 2000 to 2050 based on RGI 4.0. Methods 1, 3 and 4 are the same as described in Table 1. Method 2 is like method 1 but uses only ELA sensitivity coefficients for temperature. Median elevations from RGI 4.0 are taken as ELA in the beginning year

\begin{tabular}{|c|c|c|c|c|c|c|}
\hline \multirow[t]{2}{*}{ Method } & $\begin{array}{c}\text { Retreating glaciers } \\
\text { by } 2050\end{array}$ & Total volume in 2050 & Volume loss rate & Total area in 2050 & Area loss rate & $\begin{array}{c}\text { Global sea-level rise } \\
2000-50\end{array}$ \\
\hline & $\%$ & $\mathrm{~km}^{3}$ & $\% a^{-1}$ & $\mathrm{~km}^{2}$ & $\% a^{-1}$ & $\mathrm{~mm}$ \\
\hline 1 & 85 & 5459 & -0.76 & 63328 & -0.85 & 9.18 \\
\hline 2 & 90 & 4791 & -0.90 & 50558 & -0.95 & 10.82 \\
\hline 3 & 56 & 7836 & -0.34 & 83590 & -0.37 & 3.63 \\
\hline 4 & 54 & 7693 & -0.30 & 94356 & -0.19 & 3.80 \\
\hline
\end{tabular}


Table 3. Averaged sub-region elevation change $\left(\mathrm{m} \mathrm{a}^{-1}\right)$ estimated between 2003 and 2009 by Gardner and others (2013) and simulations with the four methods using RGI 4.0 (Section 3; Fig. 6). An ice density of $900 \mathrm{~kg} \mathrm{~m}^{-3}$ was used to convert mass balance from methods $1-4$ to elevation change. The area-weighted root-mean-square errors using methods $1-4$ are $0.052,0.075,0.024$ and $0.019 \mathrm{~m} \mathrm{a}^{-1}$, respectively

\begin{tabular}{|c|c|c|c|c|c|}
\hline Sub-region & $\begin{array}{c}\text { Gardner and others } \\
\qquad(2013)\end{array}$ & Method 1 & Method 2 & Method 3 & Method 4 \\
\hline W Tien Shan & $-0.58 \pm 0.21$ & -0.66 & -1.02 & -0.41 & -0.14 \\
\hline E Tien Shan & $-0.58 \pm 0.21$ & -1.02 & -1.73 & -0.43 & -0.93 \\
\hline W Kunlun & $0.17 \pm 0.15$ & -0.32 & -0.36 & 0.22 & 0.10 \\
\hline Qilian Shan & $-0.32 \pm 0.31$ & -0.78 & -1.11 & 0.13 & 0.03 \\
\hline$S$ and $E$ Tibet & $-0.30 \pm 0.13$ & -1.44 & -1.51 & 0.17 & -0.08 \\
\hline Hindu Kush and Karakoram & $-0.12 \pm 0.15$ & -0.33 & -0.50 & -0.12 & -0.06 \\
\hline W Himalaya & $-0.53 \pm 0.13$ & -0.29 & -0.48 & -0.20 & -0.09 \\
\hline C Himalaya & $-0.44 \pm 0.20$ & -1.17 & -1.17 & -0.52 & -0.24 \\
\hline E Himalaya & $-0.89 \pm 0.18$ & -1.38 & -1.37 & -0.41 & -0.43 \\
\hline Hengduan Shan & $-0.40 \pm 0.41$ & -2.06 & -2.07 & -0.06 & -0.31 \\
\hline All HMA & $-0.27 \pm 0.17$ & -0.78 & -0.97 & -0.18 & -0.12 \\
\hline
\end{tabular}

shrinkage rates than using RGI 2.0. The largest differences in volume loss are in the eastern Tien Shan, Pamir, western Kunlun and Qilian Shan. In the eastern Tien Shan 96\% of glaciers lost mass using RGI 4.0, far more than the $65 \%$ with RGI 2.0, and the corresponding volume loss rates are $-0.47 \% \mathrm{a}^{-1}$ and $-0.06 \% \mathrm{a}^{-1}$. Both inventories produce almost the same ratio of simulated advancing and retreating glaciers for the whole regions.

Analysis by Zhao and others (2014) showed that different volume-area scaling parameterizations can lead to $\sim 10 \%$ range in sea-level contributions. Here we show that the separation of glacier complexes into separate glaciers in HMA systematically reduces sea-level contribution by $20 \%$. The largest uncertainty, however, comes from the sensitivity of the glacier ELA to changing climate, which produces at least a $50 \%$ range in sea-level contribution. A comparison of the relative importance of the influential factors (expressed as coefficient of variation, i.e. standard deviation as a percentage of mean value) is summarized in Table 4. The ELA sensitivities to climate for each glacier and the SMB gradients with height on the glaciers cause the largest uncertainty, both of which require dedicated investigation of the method and input data. Too few field observations both of glacier mass balance, and meteorological data from the glaciated areas - are also a crucial limiting factor in providing a better estimate of sea-level rise from HMA. However, continued satellite altimetry may go far to compensating for this lack of field data, especially as longer time series allow noise smoothing on decadal timescales.

\section{ACKNOWLEDGEMENT}

This study has been supported by the National Key Science Program for Global Change Research (2012CB957702 and 2015CB953601) and the National Natural Science Foundation of China (41530748).

\section{REFERENCES}

Arendt A and 77 others (2012) Randolph Glacier Inventory [v2.0]: A Dataset of Global Glacier Outlines. (GLIMS Technical Report) Global Land Ice Measurements from Space, Boulder CO. Digital media

Table 4. Comparison of glacier volume loss and uncertainty due to different factors from 2000 to 2050

$\begin{array}{ccc}\text { Error source } & \begin{array}{c}\text { Difference in sea-level equivalent } \\ \text { (coefficient of variation) }\end{array}\end{array}$
Initial glacier outlines in RGI version 2.0 and $4.0 \quad 10.24$ and $7.89 \mathrm{~mm}(18 \%)$
Initial ELA

ELA sensitivity to daily temperature input data

$9.18,3.63$ and $3.80 \mathrm{~mm}(57 \%)$

9.18 and $10.82 \mathrm{~mm}(12 \%)$

10.24 and $5.25 \mathrm{~mm}(45 \%)$

$10.2-11.4 \mathrm{~mm}(10 \%)$

$V$-A scaling parameters
Method 1 in this paper and Zhao and others (2014) Method 1 using three initial ELA values: ELA interpolated from the first Chinese glacier inventory, median elevation in RGI 4.0 and $60 \%$-area elevation

Methods 1, 3 and 4 using ELA sensitivity to temperature prescribed from Rupper and Roe (2008) and calculated using the nearest Chinese station data and gridded data from Berkeley Earth project. The initial ELA is median elevation from RGI 4.0 Methods 1 and 2, respectively with and without ELA sensitivity to precipitation; initial ELA is median elevation from RGI 4.0

Method 1 with both untuned and tuned SMB gradients in Zhao and others (2014)
Method 1 with three sets of $V$ - $A$ scaling parameters in Zhao and others (2014) 
Arendt A and 80 others (2014) Randolph Glacier Inventory: A Dataset of Global Glacier Outlines: Version 4.0. (GLIMS Technical Report) Global Land Ice Measurements from Space, Boulder CO. Digital media

Bolch T, Menounos B and Wheate RD (2010) Landsat-based inventory of glaciers in western Canada, 1985-2005. Remote Sens. Environ., 114(1), 127-137 (doi: 10.1016/ j.rse.2009.08.015)

Bolch T and 11 others (2012) The state and fate of Himalayan Glaciers. Science, 336, 310 (doi: 10.1126/science.1215828)

Braithwaite RJ (1984) Calculation of degree-days for glacier-climate research. Z. Gletscherkd. Glazialgeol., 20, 1-20

Cuffey KM and Paterson WSB (2010) The physics of glaciers, 4th edn. Academic Press, Amsterdam

Fujita K, Ageta Y, Pu J and Yao T (2000) Mass balance of Xiao Dongkemadi Glacier on the central Tibetan Plateau from 1989 to 1995. Ann. Glaciol., 31, 159-163 (doi: 10.3189/ $17275640081820075)$

Gao X, Shi Y, Zhang D and Giorgi F (2012) Climate change in China in the 21 st century as simulated by a high resolution regional climate model. Chinese Sci. Bull., 57, 1188-1195 (doi: 10.1007/s11434-011-4935-8)

Gardner AS and 15 others (2013) A reconciled estimate of glacier contributions to sea level rise: 2003 to 2009. Science, 340(6134), 852-857 (doi: 10.1126/science.1234532)

Grinsted A (2013) An estimate of global glacier volume. Cryosphere, 7, 141-151 (doi: 10.5194/tc-7-141-2013)

Jarvis A, Reuter, HI, Nelson, A and Guevara E (2008) Hole-filled seamless SRTM data V4. International Centre for Tropical Agriculture (CIAT), Cali http://srtm.csi.cgiar.org

Kääb A, Treichler D, Nuth C and Berthier E (2015) Brief Communication. Contending estimates of 2003-2008 glacier mass balance over the Pamir-Karakoram-Himalaya. Cryosphere, 9, 557-564 (doi: 10.5194/tc-9-557-2015)

Kayastha RB, Ageta Y, Nakawo M, Fujita K, Sakai A and Matsuda Y (2003) Positive degree-day factors for ice ablation on four glaciers in the Nepalese Himalayas and Qinghai-Tibetan Plateau. Bull. Glaciol. Res., 20, 29-40

Kienholz C, Hock R and Arendt A (2013) A new semi-automatic approach for dividing glacier complexes into individual glaciers. J. Glaciol., 59(217), 925-937 (doi: 10.3189/2013JoG 12J138)

Kotlyakov BM and Krenke AN (1982) Investigation of the hydrological conditions of alpine regions by glaciological methods. IAHS Publ. 138 (Symposium at Exeter 1982 - Hydrological Aspects of Alpine and High Mountain Areas), 31-42

Krenke AN and Khodakov VG (1997) On the correlation between glacier melting and air temperature. In Kotlyakov VM ed.
34 selected papers on main ideas of Soviet glaciology (1940s1980s). Glaciological Association, Moscow, 191-207

Liu C and Ding L (1988) A primary calculation of temperature and precipitation in Tienshan mountains, China. J. Glaciol. Geocryol., 10(2), 151-160 [in Chinese with English summary]

Marzeion B, Jarosch AH and Hofer M (2012) Past and future sealevel change from the surface mass balance of glaciers. Cryosphere, 6, 1295-1322 (doi: 10.5194/tc-6-1295-2012)

Moore JC, Grinsted A, Zwinger T and Jevrejeva S (2013) Semiempirical and process-based global sea level projections. Rev. Geophys., 51, 1-39 (doi: 10.1002/rog.20015)

Nuimura T and 12 others (2015) The GAMDAM Glacier Inventory: a quality controlled inventory of Asian glaciers. Cryosphere, 9, 849-864 (doi: 10.5194/tc-9-849-2015)

Pieczonka T and Bolch T (2015) Region-wide glacier mass budgets and area changes for the Central Tien Shan between $\sim 1975$ and 1999 using Hexagon KH-9 imagery. Global Planet. Change, 128, 1-13 (doi: 10.1016/j.gloplacha.2014.11.014)

Pu JC and 6 others (2008) Rapid decrease of mass balance observed in the Xiao (Lesser) Dongkemadi Glacier, in the central Tibetan Plateau. Hydrol. Process., 22(16), 2953-2958 (doi: 10.1002/ hyp.6865. 2008)

Radić V, Bliss A, Beedlow AC, Hock R, Miles E and Cogley JG (2014) Regional and global projections of the 21st century glacier mass changes in response to climate scenarios from GCMs. Climate Dyn., 42, 37-58 (doi: 10.1007/s00382-0131719-7)

Rohde R and 8 others (2013) A new estimate of the average Earth surface land temperature spanning 1753 to 2011. Geoinfor Geostat: An Overview, 1(1) (doi: 10.4172/gigs.1000101)

Rupper S and Roe G (2008) Glacier changes and regional climate: a mass and energy balance approach. J. Climate, 21, 5384-5401 (doi: 10.1175/2008JCLI2219.1)

Shi Y, Liu YC and Kang E (2009) The Glacier Inventory of China. Ann. Glaciol., 50(53), 1-4 (doi: 10.3189/172756410790595831)

Wei Y and Fang Y (2013) Spatio-temporal characteristics of global warming in the Tibetan Plateau during the last 50 years based on a generalised temperature zone-elevation model. PLOS ONE, 8(4), e60044 (doi: 10.1371/journal.pone. 0060044)

Zhang Y, Liu S, Xie CW and Ding Y (2006) Observed degree-day factors and their spatial variation on glaciers in western China. Ann. Glaciol., 43, 301-306 (doi: 10.3189/ 172756406781811952)

Zhao L, Ding R and Moore JC (2014) Glacier volume and area change by 2050 in high mountain Asia. Global Planet. Change, 122, 197-207 (doi: 10.1016/j.gloplacha.2014.08.006) 